\title{
A Typology Of Music Consumption Motivations
}

Philip J. Trocchia, (E-mail: ptrocch@ksu.edu), Kansas State University Melissa M. Apps, TOTE

Sarah E. McNish, Kansas State University

\begin{abstract}
This study explores individual music consumption preferences using the existentialphenomenological paradigm of interpretive research. Holt's (1995) typology is employed and modified to develop a motivational framework for music consumption. Within the context of the framework, thirteen basic reasons for consuming music are presented: accounting, auditory stimulation, fantasy, memory trigger, identification, inspiration, professional development, ambiance, discussion topic, event preparation, communing, gaining acceptance, and exerting dominance. Implications for marketing practitioners and future research opportunities for marketing academicians are discussed.
\end{abstract}

\section{Introduction}

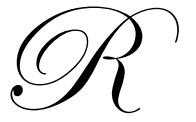

ecorded music accounts for about one-sixth of U.S. consumer entertainment expenditures and just under ten billion dollars in U.S. sales (Cother 2000; Lacher and Mizerski 1994). Increased technological innovations now make it possible to retrieve music from devices from which music formerly could not have been accessed. These devices include hand-held and desktop computers, video game systems, personal digital assistants, and even cell phones (Mossberg 2000). Additionally, new formats for recorded music, such as mini-disks and downloadable computer files, are finding their way into more and more homes every day. Because of their small size, these devices have made music consumption much more portable and convenient.

Changes in the workplace are also impacting the way people listen to music. In the past decade, dramatic changes have occurred in the traditional workplace. Corporate atmospheres are simultaneously more relaxed (Prather 2001) and results-oriented than they used to be (Frigo and Litman 2002; Halpern and Richman 2002). As a consequence, employees have increased flexibility in the manner in which they choose to work, and music is playing a more substantial role in the workplace. In fact, studies have indicated that listening to music in the office may increase workers' productivity. Subsequently, several companies are encouraging their employees to listen to music while they work (Prentice 2001).

Further, the trend toward telecommuting is also important to the music industry. An estimated ten million Americans now work out of their homes, and the movement is expected to continue well into the $21^{\text {st }}$ century (Leonhardt 1999). These individuals represent a huge potential market because they have direct control over their musical selections. These workers may substitute their own selections for the white noise and other sounds missing from the home office.

Although previous research has studied individuals' music purchases (e.g. Lacher 1989; Lacher and Mizerski 1994), no study has developed a typology documenting and describing the various motivations for why individuals decide to listen to particular musical selections. Because of 1) the vast and growing importance of prerecorded music to the lives of many consumers and 2) changes in the demographic composition of music listeners due to technological advancements and workplace restructuring, we felt that such a study could provide valuable 
Readers with comments or questions are encouraged to contact the authors via email.

contributions to marketing academics and practitioners. Since only 15 percent of the thousands of recorded compositions released annually ever earn back their initial investment (Peers 2000), further investigation regarding end-use listenership appears to be warranted.

\section{Literature Review}

There are two general categories of marketing studies involving music. The first involves the use of music as a means of influencing consumer purchase behavior (e.g. Bruner 1990; Gorn 1982). Such research goes beyond the scope of the current study. The second category involves studying patterns that underlie music consumption. For instance, Holbrook and Schindler (1989) studied the period during which musical preferences are formed. They found that musical preferences are primarily acquired between late adolescence and early adulthood. Flynn, Eastman, and Newell (1995) found that consumer behavior characteristics, such as opinion leadership, enduring involvement, perceived knowledge, and objective knowledge, were better predictors of rock music shopping behavior than were demographic variables such as age, gender, and marital status. This finding indicates that music listening is perhaps driven more by individual, rather than cultural, preferences. Lacher and Mizerski (1994) examined the decision-making process behind the purchase of rock music. They found sensorial, emotional, and analytical responses to the music all impacted subsequent purchase behavior. Although that study is highly valuable in detailing antecedents to music purchase behavior, it differs from the present study in a number of ways.

First, the current study uses an inductive approach to understand motivations for music consumption. As such, we sought to gain knowledge of individuals' music listening experiences with no preconceived notions of why they chose to consume particular musical selections. We also wanted to generate data using the words of music listeners. Further, the present study seeks to understand motivations for consuming all types of music and is not limited to rock. As such, we seek to develop a comprehensive framework regarding individual's motivations for music consumption. To do so, we employ a modified version of Holt's (1995) typology of consumption practices.

\section{Method}

Semi-structured depth interviews with informants who possessed CD collections were conducted. The existential-phenomenological (e-p) paradigm guided the structure and content of the interviews. This paradigm has been used in recent consumer research studies and seeks to derive consumer motivations, tensions, and conflicts by obliging informants to describe specific life-events pertaining to the topic of study (Thompson 1996; Thompson, Locander, and Pollio 1989). Accordingly, this method was chosen in order to tap music consumers' motives for selecting and listening to particular musical selections.

In this study, 33 students enrolled in upper-level marketing research classes conducted the interviews. Students received extensive training in phenomenological interview techniques and engaged in role playing exercises before conducting the interviews. Informants chose the setting in which the interviews were conducted in order to create a relaxed atmosphere that precipitated an open dialogue (McCracken 1988; Thompson et al. 1989). Therefore, most interviews were conducted at the informants' residence. Prior to the interviews, each informant was instructed to gather six compact disks, records, or tapes to which they either currently or had previously listened. During the interviews, participants discussed the feelings that they associated with each of the six musical entities, the circumstances under which they were most likely to listen to selections from the album, tape, or CD, and their motivations for listening to it.

Interviews lasted from 30 to 90 minutes. Informants were strategically selected members of a pool of interviewing students' friends and family and ranged in age from 16 to 65 years. 34 of the 66 study participants were female. Participants' education levels ranged from those who had graduated from high school to those with doctoral degrees.

Informants were instructed that they were part of an academic study focusing on motivations and issues pertaining to music listening preferences and that all information revealed during the interview would be kept confi- 
dential. Each interview was taped; marketing research students transcribed the recorded interviews. Typology

Music consumption is the act of listening to a piece of music (Holbrook and Anand 1990; Lacher and Mizerski 1994). The general act of consuming consists of actions in which individuals directly engage consumption objects, termed "object actions," and interactions with other people in which consumption objects serve as focal resources, or "interpersonal actions." In terms of purpose, consumers' actions can be both ends within themselves, termed "autotelic actions" and means to some further ends, or "instrumental actions" (Holt 1995). Combining these dimensions yields a two $\mathrm{x}$ two matrix that locates the four categories for music consumption that are described in the following sections (See figure 1).

\section{Quadrant I - Experiencing}

Experiencing lies at the intersection of object and autotelic actions. Applied to the context of this study, it involves directly engaging in the activity of listening to music not to achieve some goal, but as a pleasurable end in itself. Our study participants discussed numerous reasons for why they listened to particular musical selections that were classified in the experiencing category. The subcategories are termed accounting, auditory stimulation, fantasy, and memory trigger.

Accounting: Individuals engage in accounting when they apply an interpretive framework to make sense of the object they are consuming (Holt 1995). Radio listeners often engage in a somewhat basic form of accounting that may involve contemplating which artist is singing a particular song, which album or CD the selection originally appeared on, and the year in which the song was released. For other listeners, such as the respondent cited below, accounting goes beyond elaborating on these "superficial" facts and into the realm of deconstructing the content of musical passages for the sake of entertainment.

"I like to pick apart pieces of music in my head. I pick out the meter, the rhythm, the accents, so that I have a picture of the song in my head. I especially like unusual pieces, like Take Five has a quintuple meter, so it has five beats per measure. Four beats is the usual." (Male, 44, Dave Brubeck, Take Five)

Auditory Stimulation: Spectators appreciate attending athletic events when they respond emotionally to their situations, people, action, and objects (Holt 1995). Emotion is used in this context to describe the holistic, short-term feelings that spectators express in response to the game (McCarthy 1989; Schott 1979). Likewise, Holbrook and Zirlin (1985) relate that aesthetic responses involve emotional reactions to the artistry and beauty of objects or events. This response is very similar to that which many of our respondents had with music. Nearly all our respondents mentioned listening to their CDs because they liked the way the music sounded and made them feel good. Below are examples.

"You can not be upset and listen to this CD. This is the happiest shit on earth. Anytime I am feeling down, if I just play some Brian Wilson, I know I am going to crack a smile. It's cheaper than drugs. Just kidding. I love the music." (Male, 25, Brian Wilson, Imagination) "I bought (the CD) because it contains good, mellow jazz. It pleases the ears. " (Male, 35, 107 Degrees in the Shade)

Fantasy: In analyzing the interview transcripts, it was apparent that many individuals listen to music for the purpose of fantasizing. Caughey (1984) defines fantasizing as "an imagined sequence of events or mental images that serve to express unconscious conflicts and to gratify unconscious wishes (p 157)." This phenomena, also referred to as autism (Schiffman and Kanuk 2000), allows individuals to use music as a catalyst for escaping from the reality of their lives. Below are listed examples of how some respondents use music to temporarily leave their present existence behind.

"I have never seen Miles Davis play live, but I kinda have my own image of what it would be like to see him play live and I also have less literal visions of the type of imagery. Obviously this doesn't have any vocal music, so it leaves your mind a little more open to do some wandering, and so jazz for some reason, makes me think of being in 
some sort of high-rise building at night getting ready to go out on the town. I'm dressed up and I am looking out over the city in this high-rise apartment watching traffic from high above and maybe it's raining. It puts you at a distance from the outside world." (Male, 31, Miles Davis, Birth of the Cool)

The power of music is that it can take you to places that you have never been. It's like, even though I have never been to India I get a little feeling for it every time I listen to this $C D$, based on pictures I have seen, books I've read, and things I have heard. That's the power of music, I guess." (Male, 23, Ravi Shankar, Celebration)

Memory Trigger: Informants often spoke of how they used music to help them remember particular events or periods in their lives. The music was used as a device to transport them mentally back in time. For these individuals, music is employed as a memory trigger. This sub-category differs from its counterpart above, fantasy, because in this context, individuals are taking themselves to a time and place that they have experienced before. In fantasy, by contrast, the individual escapes to a locale they have never experienced. Below are examples of the use of music as a memory trigger.

"[Time After Time] reminds me of my childhood when I was young. 'Girls Just Wanna Have Fun' makes me appreciate my girlfriends and the mischief we used to get into. I feel very lucky to have such good friends with such good memories of our good times." (Female, student, 18, Cyndi Lauper, 12 Deadly Cyns...And Then Some)

"[Pink Floyd] reminds me of climbing mountains and ice climbing, getting high in Alaska and good times. It was a feeling of greatness in an unknown land, and it invokes that because the whole time I was there that's all I listened to. We'd get high and listen to Floyd and then go out hiking." (Male, 24, Pink Floyd, Pulse)

\section{Quadrant II - Goal Attainment}

This category of music consumption occurs when an individual listens to music as an instrument to achieve some goal. For example, music may be employed to enhance one's self-image or to improve a particular skill. Our respondents provided a variety of reasons for using music for the purpose of goal attainment. These reasons were clustered into four general subcategories: identification, inspiration, and professional development.

Identification: Belk (1988) found that when an individual values something in his possession, the object may serve to enhance one's self image if the possessor identifies with the object. This occurred frequently in our interviews, as informants mentioned making musical purchases and listening to music because they identified with the artist and felt proud to have the $\mathrm{CD}$ in their collections. Hence, this music is consumed not simply for the purpose of auditory stimulation, but also because it helps the individual achieve a (perhaps subconscious) goal of enhancing his or her self-image. This subcategory also clearly goes beyond appreciating the artist for his or her talent toward identifying with him or her as a person. It is apparent that the artist touches their listeners somehow and makes them feel better about themselves by purchasing and listening to their work. The artist may also provide motivation to the consumer to actively attempt to better him or herself. Below are examples of this concept that were uncovered in the interviews:

"He gives back to his community and helps inner city children from New York and I really admire that." (Female, 21, LL Cool J, Mama Said Knock You Out)

"I had heard [the album Seven] and I actually went out and bought it after I saw him on 'Oprah' and he said all of his proceeds would go towards putting kids through college in the seven days after that show. That was very motivating for me." (Female, 21, Garth Brooks, Seven)

Inspiration: Several individuals who were interviewed expressed that they listened to particular musical selections because they felt that the music either enhanced their performance in selected activities or inspired them to make it through personal crises. The music was used as an instrument toward attaining a larger personal goal. Below is an example. 
"When I broke up with [my boyfriend] I had really low self esteem because of him. I wanted to get in shape and make myself look really good. I bought this CD to listen to when I worked out I has very upbeat songs that are good to workout to." (Female, 24, Madonna, You Can Dance)

Professional Development: One individual who was interviewed (quoted below) expressed that she consumed classical music in order to develop and enhance the nuances and subtleties in the music that she plays herself. This sub-category, deemed professional development, thus concerns listening to music for the purpose of advancing one's own musical skills.

"I bought it because I am a violin major and I did not even own a classical CD before this one. I thought possibly I could learn from her." (Female, 25, Midori, Live at Carnegie Hall)

\section{Quadrant III - Socializing}

This category involves using music as a means to enhance present interactions with others. There are no specific or clear ulterior motives behind the interpersonal interactions. That is, music is used only to enhance the setting in which individuals plan to gather for a specified period of time. Interview data suggests that this category can be divided into three distinct subcategories: ambiance, discussion topic, and event preparation.

Ambiance: Often, music is used to enhance the atmosphere of a social setting. This category, then, pertains to the use of music playing in the background in a party or social situation. Music is used in this manner primarily to help make the event more enjoyable to those in attendance. The following quotes pertain to the use of music for such purposes.

"I am getting married this summer and I kind of wanted some music for it. [The music on the CD] puts me in a good and relaxed mood. It also makes me kind of anxious for my wedding day to get here. I [like this CD] because it puts me in a good mood and I think the guests will have fun with it." (Female, 23, The Ultimate Wedding Album)

Discussion Topic: Informants stated that they listen to music when in tight quarters with other individuals in order to break the potential awkward silence that might be present in the absence of music. One informant related that he keeps certain "interesting" audiotapes in the glovebox of his car so that he will have something to talk about with his passengers.

"I don't have a copy of it here, but I keep Suzanne Vega in my glovebox just as an icebreaker in case a date is going nowhere." (Male, 25, Suzanne Vega, Nine Objects of Desire)

Event Preparation: A number of respondents discussed a desire to prepare themselves for concerts they knew they were going to attend by purchasing the artist's most recent CD. Some expressed that they made the purchase in order to feel part of a group and not be inadvertently left out because of lack of knowledge of the artist. They also felt they would enjoy the experience itself more if they knew what to expect. Below is an example of a respondent quote pertaining to this matter.

"I bought this CD this past June because I was going to Lilith Fair this summer and I wanted to know the words to her songs before the concert." (Female, 24, Natalie Merchant, Tiger Lily)

\section{Quadrant IV - Bonding}

This category involves using music as a means to alter the self-image in order to achieve an ultimate goal of changing or enhancing long-term interactions and relationships with others. It has been noted that consumption practices may help individuals to achieve their self-image goals (Belk 1988). This may involve using the consumption object, music, as a device to manipulate people into seeing the actor in the manner that she or he wishes to be seen. Bonding has been broken down into three sub-classifications: communing, gaining acceptance, and exhibiting dominance. 
Communing: A number of active musical groups have devoted followings and appear to offer their "followers" a sense of community. Such groups work to promote this sense of community by avoiding commercialization and striving to make each concert a unique experience for their fans by altering the makeup of their songs in each show. Within each band's fan base, there appears to be two distinct groups: the "devoted followers" and the "pseudo fans" who believe that they are fans but, because they rarely attend concerts, are often ridiculed by the devoted followers. Those who are devoted followers are aware of the importance of attending shows and concerts. They repeatedly listen to concerts tapes (rather than the CDs or albums that the bands release for the "pseudo-fans) as a mechanism for maintaining membership within their devoted community. Below is a quote from an individual who uses music as a mechanism to embrace a communal experience.

"The Dead and Phish made it legal to tape their shows and trade them, as long as nobody made money off the shows. Phishhook.com is a perfect example of a trading community. Through that site you can trade bootleg shows with other Phish Heads all over the country. I personally have about 100 shows."

Gaining Acceptance: Some respondents indicated that they used music as a means to help satisfy their need for affiliation (Murray 1938). For these individuals, music was used as an area of common interest and a means to develop friendships and increase their popularity among peers.

"I bought the CD because some friends of mine really liked the band. It makes me feel cool because I know my friends think [The Backstreet Boys] are cool so they will think I am cool because I listen to them...Listening to the same music means we have something in common and I like having things in common with my friends." (Female, 14, Backstreet Boys, Black and Blue)

Exerting Dominance: For some, music appears to serve as an instrument to achieve a form of dominance over others. The need for dominance relates to an individual's need or desire to control his or her environment (Murray 1938). According to Schiffman and Kanuk (2000, p. 116), "Many individuals experience increased self-esteem when they exercise power over objects or people." The notion that some individuals derive a sense of power over others through music emerged in a number of interviews.

"I like to keep up with the newest bands that nobody else knows about and the latest CDs so that (my friends) will always come to me to find out what's happening in music." (Male, 22, Ministry, Sphinctour)

"I try to be informed about music by listening to [an alternative music station] so I can kind of have that (as a means of staying ahead of other people in terms of music knowledge)." (Male, 21, Elbow, Asleep in the Back)

\section{Discussion}

This paper focuses on the motives underlying music consumption. In doing so, we use Holt's (1995) typology to classify music consumption into four general categories. Experiencing focuses on one's consumption of music as an end in itself. Individuals who consume music for the purpose of goal attainment do so in order to achieve some result that goes beyond their present enjoyment of the music. The socializing motive involves consuming music in order to improve interactions with others that are taking place while listening to music. Finally, individuals who use music for bonding do so to improve their long-term and future associations with others. These general categories were further sub-divided to reflect more detailed motivations for music consumption behavior.

In terms of promoting the consumption of music, this study provides some important information for marketers. Entertainment firms may choose to focus on one or several of the motives presented in order to increase consumer interest. For example, since this study found enhancing one's social position to be a motivation for music consumption, marketers may choose to depict increased popularity as an outcome to be gained by the consumption of certain musical choices. Further, particular musical groups may be positioned as "cutting edge" in order to motivate those who are seeking dominance in the realm of musical taste to buy it and talk about it. Initial promotions of such artists may be performed through such informal methods as Internet chat rooms and personalized e-mails. Ad- 
ditionally, marketers may wish to promote music as a means for escaping reality, as in the case of the fantasy and memory trigger motivations uncovered in the experiencing quadrant. Marketers may also wish to further capitalize on the notion that music can be used as an instrument toward building a sense of community. However, this must be approached delicately. The paradox with groups with large communal followings (such as The Grateful Dead and Phish) is that they seek to avoid commercialization in terms of expanding their audiences, yet manage to make substantial sums of money from their relatively small but extremely devoted fan bases.

\section{Future Research}

There are numerous potential future research studies that could expand the line of research presented in the present manuscript. For instance, such research may examine the demographic and psychological characteristics associated with the various motivational categories. For instance, teenagers with moderate or low self-esteem are likely to consume music in order to gain acceptance, while older individuals who find their lives unfulfilling may wish to use music as a memory trigger or mechanism for fantasy. This information could be used to increase marketers' ability to cater to the needs of specific groups of individuals.

Future research might also focus on the types of music that are associated with each consumer motive. For example, as demonstrated by Holbrook and Schindler (1989), individuals develop their musical preferences in their late adolescence and early adulthood. Therefore, marketers who wish to promote music as a memory trigger will probably need to not only match the era when their target market was $17-24$ years old, but also whether certain songs are more conducive to such activity than others.

Additionally, phenomenological studies may be performed regarding several of the individual subcategories that emerged in the present study. Specifically, using music as a catalyst for communing and fantasy appear to be particularly ripe areas for qualitative inquiry. By better understanding each of the motives, marketers may be able to more accurately utilize the information that has been gathered.

Finally, because this typology provides a clean, two by two framework for categorizing different consumption practices and motivations, marketers may wish to use it to further study other consumption-related issues besides sports (Holt 1995) and music. Future studies may choose to branch out of the entertainment field, as this format appears applicable in other consumption settings such as transportation, home furnishings, apparel, and technology usage.

\section{References}

1. Belk, Russell W. (1988), "Possessions and the Extended Self," Journal of Consumer Research, (September), 169-191.

2. Bruner, Gordon C. (1990), "Mood, Music, and Marketing," Journal of Consumer Research, (September), 94-103.

3. Caughey, John L. (1984), Imaginary Social Worlds. Lincoln, NE: University of Nebraska Press.

4. Cother, Jason. (2000), Movies and Music Industry. (9 April), [available at http://www.hoovers.com/industry/snapshot/0,2204,30,00.html.

5. Flynn, Leisa Reinecke, Jacqueline K. Eastman, and Stephen J. Newell (1995), "An Exploratory Study of the Application of Neural Networks to Marketing: Predicting Rock Music Shopping Behavior," Journal of Marketing Theory \& Practice, (Spring), 75-85.

6. $\quad$ Frigo, Mark L. and Joel Litman (2002), "What is Return Driven Strategy?" Strategic Finance, 83 (8), 1113.

7. Gorn, Gerald J. (1982), "The Effects of Music in Advertising on Choice Behavior: A Classical Conditioning Approach," Journal of Marketing, 46 (winter), 94-101.

8. Halpern, William and Charles Richman (2002), "Balanced Scorecard Tool Drives Performance," Association Management, 54 (2), 26.

9. Holbrook, Morris and Punam Anand (1990), "Effects of Tempo on Responses to Music," Psychology of Music, 18, 150-162. 
10. _ _ and Robert M. Schindler (1989), "Some Exploratory Findings on the Development of Musical Tastes," Journal of Consumer Research, 16 (1), 119-124.

11. __ _ and Robert Zirlin (1985), "Artistic Creation, Artworks, and Aesthetic Appreciation" in Advances in Nonprofit Marketing, Russell Belk, ed. Greenwich, CT: JAI, 1-54.

12. Holt, Douglas B. (1995), "How Consumers Consume: A Typology of Consumption Practices," Journal of Consumer Research, 22 (1), 1-16.

13. Lacher, Kathleen T. (1989), "Hedonic Consumption: Music as a Product," in Advances in Consumer Research, Vol.16, Thomas K. Srull, ed. Provo, UT: Association for Consumer Research, 367 - 373.

14. _ _ and Richard Mizerski (1994), "An Exploratory Study of the Responses and Relationships Involved in the Evaluation of, and Intention to Purchase New Rock Music," Journal of Consumer Research, 21(2), 366-380.

15. Leonhardt, David (1999), "Telecommuting To Pick Up as Workers Iron Out Kinks," New York Times, December 20, C6.

16. McCarthy, E. Doyle (1989), "Emotions are Social Things: An Essay in the Sociology of Emotions," in The Sociology of Emotions: Original Essays and Research Papers, ed. David Franks and E. Doyle McCarthy, Greenwich, CT: JAI, 51-72.

17. McCracken, Grant (1988), The Long Interview, Sage, Newbury Park, CA.

18. Mossberg, Walter S. (2000), "Improved Hand-Helds Still Don't Capture the Magic of Palms," Wall Street Journal, May 4, B1 column 1.

19. Murray, Henry A. (1938), Explorations in Personality, New York: Oxford University Press.

20. Peers, Martin (2000), "In the Groove: Music Companies Have Come To See the Marketing Potential of the Web," Wall Street Journal, March 20, R14.

21. $\quad$ Prather, Michelle (2001), "No Turning Back," Entrepreneur, (August), 17.

22. Prentice, Claire (2001), "Work and Play," Business A.M., (July 20).

23. Schiffman, Leon G. and Leslie Lazar Kanuk (2000), Consumer Behavior, Englewood Cliffs, NJ: Prentice Hall.

24. Schott, Susan (1979), "Emotion and Social Life: A Symbolic Interactionist Analysis," American Journal of Sociology, 84 (May), 1317-1334.

25. Thompson, Craig J. (1996), "Caring Consumers: Gendered Consumption Meanings and the Juggling Lifestyle," Journal of Consumer Research, 22 (March), 388-406.

$26 . \quad$, William B. Locander, and Howard R. Pollio (1989), "Putting Consumer Experience Back into Consumer Research: The Philosophy and Method of Existential-Phenomenology," Journal of Consumer Research, 16 (September), 133-147. 